\title{
BAYESOWSKA ANALIZA TRANSFORMACJI BOXA I COXA DLA ILORAZU CEN W MODELACH FCSV
}

\begin{abstract}
$\mathrm{Z}$ a r y s t r e ś c i. Celem artykułu jest statystyczna analiza transformacji Boxa i Coxa ilorazu cen instrumentów finansowych w modelach FCSV. Stosowane jest podejście bayesowskie, które pozwala zbadać, w jakim stopniu dane modyfikują wstępne przekonanie o parametrze transformacji. Wyniki empiryczne pokazują, że założenia o rozkładzie a priori parametru transformacji ma istotny wpływ na kształt brzegowego rozkładu a posteriori tego parametru. Jednak w większości rozważanych przypadków rozkłady te, w porównaniu z rozkładami a priori, są przesunięte w kierunku zera. Zatem transformacje ilorazu cen dające wartości bliskie logarytmicznej stopie zwrotu są bardziej prawdopodobne a posteriori niż transformacje prowadzące do prostej stopy zwrotu.
\end{abstract}

S ł o w a k 1 u c z o w e: transformacja Boxa i Coxa, model SV, wnioskowanie bayesowskie.

\section{WSTĘP}

W dyskretnych modelach zmienności przedmiotem analizy są proste lub logarytmiczne stopy zwrotu. Wybór rodzaju stopy zwrotu jest arbitralny lub wynika z przyjętych założeń o ich rozkładzie. Należy podkreślić, że logarytmiczne stopy zwrotu są częściej stosowane w badaniach teoretycznych, gdyż proces logarytmu cen występuje w modelach z czasem ciagłym (w równaniach dyfuzji). Ponadto, logarytmiczne stopy zwrotu przyjmują wartości z całej osi rzeczywistej, co ułatwia ich modelowanie. $Z$ drugiej strony proste stopy zwrotu są wygodniejsze $\mathrm{w}$ analizie portfelowej. Wiadomo, że jeżeli wartość bezwzględna stopy zwrotu nie jest duże, to różnica między logarytmiczną a prostą stopa zwrotu jest niewielka. Jednak założenie dotyczące rodzaju modelowanej stopy zwrotu może mieć istotne znaczenie w zastosowaniach modelu. W wielu dyskretnych modelach wyceny opcji założenie, że warunkowy rozkład logarytmicznej stopy zwrotu jest t-Studenta implikuje nieskończoną warunkową wartość oczekiwaną ceny instrumentu podstawowego (przez co niespelnione są założenia, z których wynikają wzory na cenę opcji, zob. Duan, 1999). W takich 
przypadkach wykorzystuje się proste stopy zwrotu (zob. np. Hafner i Harwartz, 1999; Härdle i Hafner, 2000; Bauwens i Lubrano, 2002). Jednak zarówno prosta jak i logarytmiczna stopa zwrotu są transformacjami Boxa i Coxa ilorazu cen instrumentu finansowego, z parametrem $\lambda$ równym, odpowiednio, 1 i 0 . Celem artykułu jest statystyczna analiza transformacji Boxa i Coxa dla danych finansowych. Parametr transformacji, $\lambda$, jest bowiem estymowany wraz $z$ innymi parametrami modelu (por. Zellner, 1971).

W drugiej części pracy przedstawiamy bayesowskie modele FCSV dla transformowanych danych. Wyniki empiryczne, związane z modelowaniem zmienności indeksów giełdowych, zamieściliśmy w trzeciej części. Natomiast cześć czwarta zawiera uwagi końcowe.

\section{BAYESOWSKIE MODELE FCSV DLA TRANSFORMOWANYCH ZMIENNYCH}

Niech $\left\{x_{t}, t=0,1, \ldots, T\right\}$ oznacza szereg czasowy cen instrumentu finansowego w chwili $t$. Przedmiotem modelowania są ilorazy cen po transformacji Boxa i Coxa:

$$
B\left(x_{t} / x_{t-1}, \lambda\right)= \begin{cases}\frac{\left(x_{t} / x_{t-1}\right)^{\lambda}-1}{\lambda} & \lambda>0, \\ \ln \left(x_{t} / x_{t-1}\right) & \lambda=0 .\end{cases}
$$

Dla transformowanych danych przyjęto strukturę $\operatorname{AR}(1)$ :

$$
B\left(x_{t} / x_{t-1}, \lambda\right)-\delta_{1}=\rho_{1}\left(B\left(x_{t-1} / x_{t-2}, \lambda\right)-\delta_{1}\right)+\xi_{t}, \quad t=1,2, \ldots, T,
$$

gdzie $\left\{\xi_{t}\right\}$ jest procesem FCSV (ang. Fat-Tailed and Correlated Stochastic Volatility Process, zob. Jacquier, Polson i Rossi, 2004). Dla $\lambda=0$ przedmiotem modelowania są logarytmiczne stopy zwrotu, natomiast przy $\lambda=1$ otrzymujemy równanie autoregresyjne dla prostej stopy zwrotu.

O zmiennych losowych $\xi_{t}$ zakładamy, że dla każdego $t \in\{1,2, \ldots, T\}$ :

$$
\xi_{t}=u_{t} \sqrt{h_{t} / \omega_{t}}, \quad \ln h_{t}=\gamma+\phi \ln h_{t-1}+\sigma_{h} \eta_{t},
$$

gdzie $\omega_{t} \sim \chi^{2}(v) / v$ i $\omega_{t} \perp\left(u_{s}, \eta_{s}\right)$ dla $t, s \in\{1,2, \ldots, T\}$ oraz

$$
\left(u_{t}, \eta_{t}\right)^{\prime} \sim \operatorname{iiN}\left(0,\left(\begin{array}{cc}
1 & \rho \\
\rho & 1
\end{array}\right)\right) .
$$

Zapis iiN oznacza ciąg niezależnych zmiennych losowych o rozkładzie normalnym, natomiast symbol $\perp$ oznacza, że zmienne losowe są niezależne.

Proces FCSV umożliwia modelowanie podstawowych własności finansowych szeregów czasowych, takich jak: 1) grube ogony - nawet gdy $\phi=0$ oraz $v=\infty$, kurtoza $\xi_{t}$ jest większa niż kurtoza zmiennej losowej o rozkładzie nor- 
malnym; 2) efekt dźwigni, o którym informuje ujemna wartość parametru $\rho$ (jeśli zmienne losowe $u_{t}$ i $\eta_{t}$ są ujemnie skorelowane, to ujemne wartości zmiennej losowej $u_{t}$ są związane ze wzrostem wartości zmiennej ukrytej $h_{t} \mathrm{~W}$ tej samej chwili, i w konsekwencji w następnym czasie); 3) skupianie się zmienności wartości parametru $\phi$ bliskie jeden świadczą o dużym nasileniu tego zjawiska; 4) zmienność wariancji warunkowej (wahliwość zmienności), która jest tym większa im wyższa jest wartość parametru $\sigma_{h}^{2}$.

Aby model bayesowski był kompletny, konieczna jest specyfikacja rozkładu a priori na przestrzeni nieznanych parametrów tego modelu. Przyjęto następującą strukturę rozkładu a priori (zob. Pajor, 2003):

$$
p\left(\delta_{1}, \rho_{1}, \gamma, \phi, v, \sigma_{h}^{2}, \rho, \lambda\right)=p\left(\delta_{1}\right) p\left(\rho_{1}\right) p(\gamma) p(\phi) p(v) p\left(\sigma_{h}^{2}, \rho\right) p(\lambda) .
$$

Parametr $\delta_{1}$ ma standardowy rozkład normalny. Dla parametru autoregresji $\left(\rho_{1}\right)$ założyliśmy rozkład jednostajny na przedziale $(-1 ; 1)$. Wstępna wiedza o parametrach $\gamma$ i $\phi$ jest reprezentowana przez rozkłady normalne o wartości oczekiwanej równej zero i odchyleniu standardowym 10, przy czym rozkład dla $\phi$ jest ucięty restrykcja, że $|\phi|<1$. Dla parametru stopni swobody $(v)$ przyjęliśmy rozkład wykładniczy o wartości oczekiwanej i odchyleniu standardowym równym 10 (podobnie jak w pracy Osiewalski i Pipień, 1999). Wektor $\left(\rho, \sigma_{h}^{2}\right)$ posiada niestandardowy rozkład a priori:

$p\left(\sigma^{2}, \rho\right)=s_{0}{ }^{v_{0}} \Gamma\left(v_{0}\right)^{-1} p_{0}^{0.5}(2 \pi)^{-0.5}\left(\sigma_{h}^{-2}\right)^{v_{0}+1} e^{-\frac{s_{0}}{\left(1-\rho^{2}\right) \sigma_{h}^{2}}}\left(1-\rho^{2}\right)^{-v_{0}-1.5} e^{-\frac{\left(\rho \sigma-\psi_{0}\right)^{2} p_{0}}{2\left(1-\rho^{2}\right) \sigma_{h}^{2}}}$, gdzie $v_{0}=1, s_{0}=0,005, \psi_{0}=0, p_{0}=2$, (por. Jacquier, Polson i Rossi, 2004).

Natomiast, dla parametru transformacji Boxa i Coxa $(\lambda)$ rozważamy cztery rozkłady a priori:

A) niestandardowy, symetryczny, rozkład U-kształtny na odcinku $[0 ; 1]$, tak by wartościom bliskim 0 oraz 1 nadać a priori duże prawdopodobieństwo:

$p(\lambda) \propto e^{-\beta x(1-x)}$, gdzie $\beta=30$;

B) rozkład beta na odcinku $(0 ; 1)$ o parametrach 0,5 i 0,5 ;

C) rozkład jednostajny na odcinku $[0 ; 1]$;

D) rozkład wykładniczy, określony na przedziale $[0 ;+\infty)$, o średniej równej 1. Bayesowski model statystyczny jest scharakteryzowany przez gęstość łącznego rozkładu wektora ilorazu cen $\left(\mathrm{tj} . y=\left(y_{1}, \ldots, y_{T}\right)^{\prime}\right.$, gdzie $\left.y_{t}=x_{t} / x_{t-1}\right)$, wektorów zmiennych ukrytych $\left(\mathrm{tj} . h=\left(h_{1}, \ldots, h_{T}\right)^{\prime}\right.$ i $\left.\omega=\left(\omega_{1}, \ldots, \omega_{T}\right)^{\prime}\right)$ oraz wektora parametrów $\theta=\left(\delta_{1}, \rho_{1}, \gamma, \phi, v, \sigma_{h}^{2}, \rho, \lambda\right)^{\prime}$ :

$$
p\left(y, h, \omega, \theta \mid y_{(0)}\right)=p\left(y, h, \omega \mid \theta, y_{(0)}\right) p(\theta),
$$


gdzie:

$$
\begin{aligned}
& p\left(y, h, \omega \mid \theta, y_{(0)}\right)=p(\omega \mid v) \prod_{t=1}^{T} \frac{1}{2 \pi} \omega_{t}^{0,5} h_{t}^{-1,5}\left|\Sigma^{*}\right|^{-\frac{1}{2}} \\
& \exp \left\{-\frac{1}{2} \operatorname{tr}\left(\Sigma^{*-1} \sum_{t=1}^{T} r_{t} r_{t}^{\prime}\right)\right\}|J(\lambda, y)| \\
& p(\omega \mid v)=\prod_{t=1}^{T}\left(\frac{v}{2}\right)^{\frac{v}{2}} \Gamma\left(\frac{v}{2}\right)^{-1} \omega_{t}^{\frac{v}{2}-1} \exp \left(-\frac{v}{2} \omega_{t}\right) I_{(0,+\infty)}\left(\omega_{t}\right), \\
& \Sigma^{*}=\left(\begin{array}{cc}
1 & \rho \sigma_{h} \\
\rho \sigma_{h} & \sigma_{h}^{2}
\end{array}\right), r_{t}=\left(u_{t}, \sigma \eta_{t}\right)^{\prime},
\end{aligned}
$$

$y_{(0)}$ oznacza wektor warunków początkowych (m.in. wartość początkowa procesu $\ln h_{t}$ jest stała: $\left.\ln h_{0}=0\right),|J(\lambda, y)|$ jest wartością bezwzględną wyznacznika macierzy Jacobiego dla transformacji zmiennych: $J(\lambda, y)=\prod_{t=1}^{T} y_{t}^{\lambda-1}$.

Gęstość łącznego rozkładu a posteriori przyjmuje więc postać:

$$
\begin{aligned}
p\left(h, \omega, \theta \mid y, y_{(0)}\right) \propto p(\theta) p(\omega \mid v) & \prod_{t=1}^{T} \frac{1}{2 \pi} \omega_{t}^{0,5} h_{t}^{-1,5}\left|\Sigma^{*}\right|^{-\frac{1}{2}} \\
& \exp \left\{-\frac{1}{2} \operatorname{tr}\left(\Sigma^{*-1} \sum_{t=1}^{T} r_{t} r_{t}{ }^{\prime}\right)\right\}|J(\lambda, y)| .
\end{aligned}
$$

Rozkład ten odzwierciedla wiedzę o parametrach modelu i zmiennych ukrytych, uzyskaną na podstawie rozkładu a priori oraz informacji zawartej w danych.

\section{WYNIKI EMPIRYCZNE}

Przedmiotem rozważań są notowania dziesięciu indeksów giełdowych. Pod uwagę wzięto indeksy: WIG20, DJIA, NIKKEI 225, S\&P 500, NASDAQ 100, FTSE 100, HANG SENG, CAC 40, SPTSE 60 i DAX. Dane pochodzą ze strony http://finance.yahoo.com. W tabeli 1 zamieściliśmy podstawowe charakterystyki próbkowe oraz okresy, z których pochodzą obserwacje.

\footnotetext{
${ }^{1}$ Prezentowane w tej cześci pracy wyniki zostały uzyskane za pomocą metod Monte Carlo opartych na łańcuchach Markowa (wykorzystano losowanie Gibbsa oraz algorytm Metropolisa i Hastingsa, zob. Pajor, 2003). Zarówno wartości oczekiwane, jak i odchylenia standardowe a posteriori zostały obliczone na podstawie próby pseudolosowej, pochodzącej z łącznego rozkładu a posteriori (są to więc charakterystyki tej próby).
} 
Analizując statystyki opisowe szeregów ilorazów notowań indeksów giełdowych, należy stwierdzić, że średnie tych szeregów są bardzo bliskie jeden, ze stosunkowo niewielkim odchyleniem standardowym. Duże wartości kurtozy wskazują na to, że rozkłady empiryczne mają grubsze ogony od ogonów rozkładu normalnego.

Tabela 1. Charakterystyki próbkowe ilorazu cen

\begin{tabular}{|c|c|c|c|c|c|}
\hline $\begin{array}{c}\text { szereg czasowy } \\
\left(X_{t} / X_{t-1}\right)\end{array}$ & $\begin{array}{c}\text { okres } \\
\text { od: }- \text { do: }\end{array}$ & $\begin{array}{c}\text { liczba } \\
\text { obserwacji }\end{array}$ & średnia & $\begin{array}{c}\text { odchylenie } \\
\text { standardowe }\end{array}$ & kurtoza \\
\hline WIG20 & $02.01 .2001-13.02 .2009$ & 2035 & 1,0000 & 0,0162 & 4,9800 \\
\hline S\&P500 & $03.01 .2002-06.03 .2009$ & 1805 & 0,9998 & 0,0139 & 13,3286 \\
\hline NIKKEI 225 & $07.01 .2002-06.03 .2009$ & 1760 & 0,9999 & 0,0163 & 11,3553 \\
\hline FTSE100 & $03.01 .2002-06.03 .2009$ & 1813 & 0,9999 & 0,0137 & 10,9021 \\
\hline DAX & $03.01 .2002-06.03 .2009$ & 1825 & 1,0000 & 0,0169 & 8,6642 \\
\hline NASDAQ 100 & $03.01 .2002-06.03 .2009$ & 1808 & 1,0000 & 0,0178 & 7,8639 \\
\hline CAC40 & $03.01 .2002-06.03 .2009$ & 1838 & 0,9998 & 0,0159 & 9,7031 \\
\hline SPTSE60 & $03.01 .2002-06.03 .2009$ & 1798 & 1,0001 & 0,0132 & 14,2830 \\
\hline HANG SENG & $03.01 .2002-06.03 .2009$ & 1789 & 1,0002 & 0,0164 & 15,0382 \\
\hline DJIA & $02.01 .2001-13.02 .2009$ & 2039 & 0,9999 & 0,0130 & 12,5726 \\
\hline
\end{tabular}

Źródło: obliczenia własne.

Tabela 2. Wartości oczekiwane oraz ( $\mathrm{w}$ nawiasach) odchylenia standardowe a posteriori parametrów modelu AR(1)-FCSV - przypadek C

\begin{tabular}{|c|c|c|c|c|c|c|c|c|c|c|}
\hline $\begin{array}{l}\text { para- } \\
\text { metr }\end{array}$ & $\begin{array}{l}\text { WIG } \\
20\end{array}$ & $\begin{array}{l}\text { S\&P } \\
500\end{array}$ & $\begin{array}{c}\text { NIKKEI } \\
225\end{array}$ & $\begin{array}{c}\text { FTSE } \\
100\end{array}$ & DAX & $\begin{array}{c}\text { NAS-DAQ } \\
100\end{array}$ & $\begin{array}{c}\text { CAC } \\
40\end{array}$ & $\begin{array}{c}\text { SPTSE } \\
60\end{array}$ & $\begin{array}{l}\text { HANG } \\
\text { SENG }\end{array}$ & DJIA \\
\hline$\delta_{1} * 10^{4}$ & $\begin{array}{c}4,7 \\
(3,2)\end{array}$ & $\begin{array}{c}4,7 \\
(1,6)\end{array}$ & $\begin{array}{c}6,5 \\
(2,6)\end{array}$ & $\begin{array}{c}5,4 \\
(1,6)\end{array}$ & $\begin{array}{c}9,7 \\
(2,2)\end{array}$ & $\begin{array}{c}5,8 \\
(2,6)\end{array}$ & $\begin{array}{c}6,6 \\
(2,0)\end{array}$ & $\begin{array}{c}8,7 \\
(1,8)\end{array}$ & $\begin{array}{c}7,2 \\
(2,4)\end{array}$ & $\begin{array}{c}4,1 \\
(1,6)\end{array}$ \\
\hline$\rho_{1}$ & $\begin{array}{c}0,027 \\
(0,023)\end{array}$ & $\begin{array}{l}-0,095 \\
(0,023)\end{array}$ & $\begin{array}{l}-0,034 \\
(0,024) \\
\end{array}$ & $\begin{array}{l}-0,092 \\
(0,024) \\
\end{array}$ & $\begin{array}{l}-0,059 \\
(0,023) \\
\end{array}$ & $\begin{array}{c}-0,07 \\
(0,024)\end{array}$ & $\begin{array}{c}-0,08 \\
(0,023) \\
\end{array}$ & $\begin{array}{c}-0,06 \\
(0,024)\end{array}$ & $\begin{array}{c}0,005 \\
(0,023) \\
\end{array}$ & $\begin{array}{l}-0,074 \\
(0,022) \\
\end{array}$ \\
\hline$\gamma$ & $\begin{array}{l}-0,622 \\
(0,119)\end{array}$ & $\begin{array}{l}-0,332 \\
(0,048)\end{array}$ & $\begin{array}{l}-0,429 \\
(0,068)\end{array}$ & $\begin{array}{l}-0,357 \\
(0,052)\end{array}$ & $\begin{array}{l}-0,328 \\
(0,049)\end{array}$ & $\begin{array}{l}-0,297 \\
(0,048)\end{array}$ & $\begin{array}{l}-0,335 \\
(0,047)\end{array}$ & $\begin{array}{l}-0,493 \\
(0,074)\end{array}$ & $\begin{array}{l}-0,408 \\
(0,069)\end{array}$ & $\begin{array}{l}-0,348 \\
(0,051)\end{array}$ \\
\hline$\phi$ & $\begin{array}{c}0,928 \\
(0,014) \\
\end{array}$ & $\begin{array}{r}0,965 \\
(0,005) \\
\end{array}$ & $\begin{array}{c}0,951 \\
(0,008) \\
\end{array}$ & $\begin{array}{c}0,962 \\
(0,006) \\
\end{array}$ & $\begin{array}{c}0,963 \\
(0,006) \\
\end{array}$ & $\begin{array}{c}0,966 \\
(0,006) \\
\end{array}$ & $\begin{array}{c}0,963 \\
(0,005) \\
\end{array}$ & $\begin{array}{c}0,948 \\
(0,008) \\
\end{array}$ & $\begin{array}{c}0,955 \\
(0,008) \\
\end{array}$ & $\begin{array}{c}0,963 \\
(0,005) \\
\end{array}$ \\
\hline$\sigma_{h}^{-2}$ & $\begin{array}{c}22,23 \\
(5,675)\end{array}$ & $\begin{array}{c}16,97 \\
(2,809) \\
\end{array}$ & $\begin{array}{c}17,71 \\
(3,395)\end{array}$ & $\begin{array}{c}13,73 \\
(2,123)\end{array}$ & $\begin{array}{c}15,23 \\
(2,592) \\
\end{array}$ & $\begin{array}{c}25,79 \\
(5,279)\end{array}$ & $\begin{array}{c}15,97 \\
(2,491)\end{array}$ & $\begin{array}{c}13,67 \\
(2,447)\end{array}$ & $\begin{array}{c}15,96 \\
(3,156)\end{array}$ & $\begin{array}{c}17,87 \\
(2,996) \\
\end{array}$ \\
\hline$\rho$ & $\begin{array}{l}-0,153 \\
(0,081)\end{array}$ & $\begin{array}{l}-0,607 \\
(0,063)\end{array}$ & $\begin{array}{c}-0,55 \\
(0,065)\end{array}$ & $\begin{array}{l}-0,578 \\
(0,061)\end{array}$ & $\begin{array}{l}-0,612 \\
(0,059)\end{array}$ & $\begin{array}{l}-0,492 \\
(0,081)\end{array}$ & $\begin{array}{c}-0,62 \\
(0,063)\end{array}$ & $\begin{array}{l}-0,484 \\
(0,067)\end{array}$ & $\begin{array}{l}-0,372 \\
(0,075)\end{array}$ & $\begin{array}{c}-0,55 \\
(0,064)\end{array}$ \\
\hline$v$ & $\begin{array}{l}23,04 \\
(9,96) \\
\end{array}$ & $\begin{array}{c}27,20 \\
(11,45) \\
\end{array}$ & $\begin{array}{c}38,47 \\
(14,52) \\
\end{array}$ & $\begin{array}{c}39,75 \\
(14,61) \\
\end{array}$ & $\begin{array}{c}31,77 \\
(12,76) \\
\end{array}$ & $\begin{array}{c}30,34 \\
(12,06) \\
\end{array}$ & $\begin{array}{c}31,33 \\
(12,55) \\
\end{array}$ & $\begin{array}{c}37,85 \\
(14,55) \\
\end{array}$ & $\begin{array}{l}16,04 \\
(7,22) \\
\end{array}$ & $\begin{array}{c}26,99 \\
(11,17) \\
\end{array}$ \\
\hline$\lambda$ & $\begin{array}{c}0,397 \\
(0,255)\end{array}$ & $\begin{array}{c}0,472 \\
(0,265)\end{array}$ & $\begin{array}{c}0,504 \\
(0,266)\end{array}$ & $\begin{array}{c}0,448 \\
(0,263)\end{array}$ & $\begin{array}{c}0,405 \\
(0,256)\end{array}$ & $\begin{array}{c}0,387 \\
(0,253)\end{array}$ & $\begin{array}{c}0,399 \\
(0,255)\end{array}$ & $\begin{array}{c}0,497 \\
(0,266)\end{array}$ & $\begin{array}{c}0,401 \\
(0,256)\end{array}$ & $\begin{array}{c}0,433 \\
(0,262)\end{array}$ \\
\hline
\end{tabular}

Źródło: obliczenia własne.

Tabela 2 zawiera podstawowe charakterystyki brzegowych rozkładów a posteriori parametrów modelu FCSV przy założeniu, że rozkład a priori parametru $\lambda$ jest jednostajny na przedziale $[0 ; 1]$. Należy podkreślić, że tylko charakterystyki brzegowego rozkładu a posteriori parametru $\lambda$ silnie zależą od roz- 
kładu a priori dla tego parametru. Natomiast charakterystyki pozostałych parametrów wydają się być niewrażliwe na wybór rozkładu a priori dla parametru transformacji. Dlatego też w tabeli 3 zamieszczamy tylko wartości oczekiwane i odchylenia standardowe a posteriori parametru $\lambda$ uzyskane w modelu FCSV $\mathrm{z}$ wykładniczym rozkładem a priori dla $\lambda$. Natomiast U-kształtne rozkłady a priori na przedziale $(0 ; 1)$ (przypadek A i B) implikują U-kształtne brzegowe rozkłady a posteriori tego parametru (zobacz tabela 7 ).

Tabela 3. Wartości oczekiwane oraz (w nawiasach) odchylenia standardowe a posteriori parametru $\lambda \mathrm{w}$ modelu AR(1)-FCSV - przypadek D

\begin{tabular}{|c|c|c|c|c|c|c|c|c|c|c|}
\hline para-metr & WIG & S\&P & NIKKEI & FTSE & DAX & NASDAQ & CAC & SPTSE & HANG & DJIA \\
& 20 & 500 & 225 & 100 & & 100 & 40 & 60 & SENG & \\
\hline$\lambda$ & 0,431 & 0,666 & 0,801 & 0,579 & 0,45 & 0,412 & 0,44 & 0,798 & 0,437 & 0,531 \\
& $(0,371)$ & $(0,556)$ & $(0,624)$ & $(0,497)$ & $(0,382)$ & $(0,35)$ & $(0,377)$ & $(0,652)$ & $(0,376)$ & $(0,453)$ \\
\hline
\end{tabular}

Źródło: obliczenia własne.

Brzegowe rozkłady a posteriori parametrów struktury autoregresyjnej ( $\delta$ i $\rho_{1}$ ) są zlokalizowane $\mathrm{w}$ pobliżu zera. W większości przypadków parametr $\rho_{1}$ wskazuje na niewielką, ujemną autokorelację transformowanych zmiennych (choć w wielu przypadkach wykorzystując test Lindleya nie będzie można odrzucić hipotezy, że $\rho_{1}=0$ ). Charakterystyki rozkładu $\phi$ wskazują na skupianie się zmienności - najsilniejsze dla indeksu NASDAQ 100, najsłabsze dla indeksu WIG20. Indeks SPTSE 60 cechuje się największą wahliwością zmienności (o czym informuje parametr $\sigma_{h}^{-2}$ ), zaś najmniejszą wahliwość zmienności posiada indeks NASDAQ 100. Obserwujemy wysokie wartości oczekiwane $a$ posteriori dla parametru liczby stopni swobody. Najmniejszą wartość, równą około 16, otrzymaliśmy dla indeksu HANG SENG. Kolejne wartości są powyżej 20. Wyniki pokazują, że wprowadzenie zmiennych ukrytych pozwala dobrze modelować pojawianie się obserwacji nietypowych bez wykorzystywania rozkładów warunkowych o bardzo grubych ogonach. We wszystkich przypadkach wartość oczekiwana a posteriori dla parametru $\rho$ jest ujemna, co wskazuje na występowanie tzw. efektu dźwigni i grubszy lewy ogon rozkładu zmiennej $\xi_{t}$.

Przejdźmy do charakterystyk brzegowego rozkładu a posteriori parametru $\lambda$. Przyjrzyjmy się najpierw wynikom uzyskanym przy założeniu, że $\lambda \leq 1$. W modelach tych, charakterystyki brzegowego rozkładu a posteriori parametru $\lambda$ są bliskie charakterystykom rozkładu a priori. Odchylenia standardowe są tylko nieco niższe, zaś średnie w większości przypadków przesunięte w kierunku zera. W tabeli 4 przedstawiono kwantyle rozkładów a posteriori parametru transformacji dla czterech rozważanych rozkładów a priori. W ośmiu przypadkach mediana jest poniżej 0,5 , czyli wartości bliższe zero są bardziej prawdopodobne a posteriori niż wartości w bliskim otoczeniu 1 . Porównując rozkłady a priori $\mathrm{z}$ rozkładami a posteriori, można stwierdzić, że te ostatnie dla ośmiu indeksów 
giełdowych (wyjątek stanowią indeksy NIKKEI 225 i SPTSE 60) charakteryzują się większą masą prawdopodobieństwa na lewo od wartości 0,5 .

Tabela 4. Kwantyle rozkładów a posteriori parametru $\lambda$

\begin{tabular}{|c|c|c|c|c|c|c|c|c|c|c|c|}
\hline & $\begin{array}{c}\text { kwantyl } \\
\text { rzedu: }\end{array}$ & $\begin{array}{c}\text { WIG } \\
20\end{array}$ & $\begin{array}{c}\text { S\&P } \\
500\end{array}$ & $\begin{array}{c}\text { NIKKEI } \\
225\end{array}$ & $\begin{array}{c}\text { FTSE } \\
100\end{array}$ & DAX & $\begin{array}{c}\text { NASDAQ } \\
100\end{array}$ & $\begin{array}{c}\text { CAC } \\
40\end{array}$ & $\begin{array}{c}\text { SPTSE } \\
60\end{array}$ & $\begin{array}{c}\text { HANG } \\
\text { SENG }\end{array}$ & DJIA \\
\hline \hline & 0,05 & 0,003 & 0,004 & 0,005 & 0,004 & 0,003 & 0,003 & 0,003 & 0,005 & 0,003 & 0,004 \\
\hline & 0,25 & 0,016 & 0,023 & 0,033 & 0,021 & 0,016 & 0,015 & 0,016 & 0,031 & 0,016 & 0,019 \\
\hline A & 0,5 & 0,042 & 0,082 & 0,824 & 0,062 & 0,044 & 0,039 & 0,042 & 0,665 & 0,042 & 0,055 \\
\hline & 0,75 & 0,135 & 0,957 & 0,972 & 0,937 & 0,161 & 0,111 & 0,144 & 0,970 & 0,133 & 0,914 \\
\hline & 0,95 & 0,988 & 0,995 & 0,996 & 0,993 & 0,989 & 0,985 & 0,988 & 0,996 & 0,988 & 0,992 \\
\hline \hline & 0,05 & 0,005 & 0,011 & 0,016 & 0,008 & 0,005 & 0,005 & 0,004 & 0,013 & 0,004 & 0,007 \\
\hline & 0,25 & 0,088 & 0,163 & 0,217 & 0,131 & 0,095 & 0,081 & 0,088 & 0,194 & 0,087 & 0,116 \\
\hline B & 0,5 & 0,277 & 0,433 & 0,516 & 0,375 & 0,294 & 0,260 & 0,280 & 0,489 & 0,278 & 0,343 \\
\hline & 0,75 & 0,573 & 0,746 & 0,806 & 0,693 & 0,597 & 0,545 & 0,575 & 0,787 & 0,576 & 0,658 \\
\hline & 0,95 & 0,939 & 0,981 & 0,987 & 0,973 & 0,945 & 0,926 & 0,939 & 0,985 & 0,938 & 0,963 \\
\hline \hline & 0,05 & 0,042 & 0,063 & 0,076 & 0,055 & 0,044 & 0,04 & 0,042 & 0,072 & 0,043 & 0,051 \\
\hline & 0,25 & 0,185 & 0,252 & 0,286 & 0,229 & 0,192 & 0,178 & 0,186 & 0,278 & 0,188 & 0,215 \\
\hline C & 0,5 & 0,362 & 0,462 & 0,506 & 0,429 & 0,374 & 0,350 & 0,366 & 0,496 & 0,369 & 0,409 \\
\hline & 0,75 & 0,585 & 0,686 & 0,723 & 0,656 & 0,597 & 0,571 & 0,589 & 0,716 & 0,591 & 0,636 \\
\hline & 0,95 & 0,864 & 0,914 & 0,929 & 0,901 & 0,871 & 0,855 & 0,865 & 0,926 & 0,867 & 0,891 \\
\hline \hline & 0,05 & 0,034 & 0,058 & 0,077 & 0,047 & 0,036 & 0,032 & 0,035 & 0,071 & 0,034 & 0,044 \\
\hline & 0,25 & 0,158 & 0,252 & 0,322 & 0,213 & 0,167 & 0,153 & 0,161 & 0,307 & 0,16 & 0,196 \\
\hline $\mathrm{D}$ & 0,5 & 0,332 & 0,520 & 0,652 & 0,445 & 0,351 & 0,320 & 0,341 & 0,630 & 0,337 & 0,411 \\
\hline & 0,75 & 0,598 & 0,932 & 1,13 & 0,805 & 0,629 & 0,574 & 0,615 & 1,122 & 0,610 & 0,740 \\
\hline & 0,95 & 1,172 & 1,771 & 2,037 & 1,577 & 1,208 & 1,110 & 1,186 & 2,095 & 1,186 & 1,435 \\
\hline
\end{tabular}

Rozkład a priori dla parametru $\lambda$ : A - niestandardowy, U-kształtny na odcinku [0; 1], B - rozkład beta na odcinku $(0 ; 1), \mathrm{C}$ - rozkład jednostajny na odcinku $[0 ; 1]$, D- rozkład wykładniczy

Źródło: obliczenia własne.

W tabeli 5 przedstawiliśmy prawdopodobieństwa a posteriori tego że $\lambda \in(0 ; 0,01)$ oraz $\lambda \in(0,99 ; 1)$. Tylko dla indeksu NIKKEI 225 prawdopodobieństwo wartości bliskich jeden jest wyższe niż wartości bliskich zero.

Również w modelu FCSV z wykładniczym rozkładem a priori parametru $\lambda$, określonym na przedziale $[0 ;+\infty)$, w siedmiu przypadkach mediany rozkładów a posteriori są niższe niż 0,5 . Wyjątek stanowią indeksy NIKKEI 225 , SPTSE 60 i S\&P 500, dla których rozkłady te mają najgrubsze ogony. Należy jednak zauważyć, że we wszystkich przypadkach co najmniej 50\% masy prawdopodobieństwa znajduje się $\mathrm{w}$ przedziale $[0 ; 0,652]$, podczas gdy mediana rozkładu a priori jest równa 0,71 . Podobnie trzeci kwartyl rozkładu a priori wynosi 1,41 , natomiast dla wszystkich indeksów giełdowych trzeci kwartyl rozkładu a posteriori jest od niego niższy. W tabeli 7 przedstawiliśmy brzegowe gęstości rozkładów a priori oraz a posteriori parametru $\lambda$, uzyskane w modelach FCSV dla indeksu WIG20. Natomiast w tabela 6 umieściliśmy wybrane rozkłady, otrzymane dla indeksu NIKKEI 225. 
Tabela 5. Prawdopodobieństwa $a$ posteriori wybranych przedziałów wartości parametru $\lambda$, uzyskane w modelach FCSV przy założeniu, że $\lambda \in[0 ; 1]$

\begin{tabular}{|c|c|c|c|c|c|c|c|c|c|c|}
\hline \multicolumn{11}{|c|}{ A } \\
\hline Indeks: & $\begin{array}{l}\text { WIG } \\
20\end{array}$ & $\begin{array}{l}\text { S\&P } \\
500\end{array}$ & $\begin{array}{c}\text { NIKKEI } \\
225\end{array}$ & $\begin{array}{c}\text { FTSE } \\
100 \\
\end{array}$ & DAX & $\begin{array}{c}\text { NASDAQ } \\
100\end{array}$ & $\begin{array}{c}\text { CAC } \\
40\end{array}$ & $\begin{array}{c}\text { SPTSE } \\
60\end{array}$ & $\begin{array}{l}\text { HANG } \\
\text { SENG }\end{array}$ & DJIA \\
\hline$a=\operatorname{Pr}(\lambda<0.01 \mid y)$ & 0,173 & 0,127 & 0,102 & 0,142 & 0,172 & 0,178 & 0,172 & 0,105 & 0,174 & 0,149 \\
\hline$b=\operatorname{Pr}(\lambda>0.99 \mid y)$ & 0,041 & 0,083 & 0,109 & 0,068 & 0,044 & 0,038 & 0,042 & 0,100 & 0,040 & 0,060 \\
\hline $\mathbf{a} / \mathbf{b}$ & 4,238 & 1,531 & 0,934 & 2,088 & 3,942 & 4,693 & 4,111 & 1,052 & 4,370 & 2,492 \\
\hline \multicolumn{11}{|c|}{ B } \\
\hline$a=\operatorname{Pr}(\lambda<0.01 \mid y)$ & 0,077 & 0,050 & 0,040 & 0,060 & 0,073 & 0,081 & 0,079 & 0,045 & 0,081 & 0,064 \\
\hline$b=\operatorname{Pr}(\lambda>0.99 \mid y)$ & 0,018 & 0,035 & 0,044 & 0,030 & 0,019 & 0,016 & 0,018 & 0,039 & 0,017 & 0,024 \\
\hline$a / b$ & 4,294 & 1,418 & 0,913 & 1,999 & 3,829 & 4,924 & 4,402 & 1,137 & 4,769 & 2,656 \\
\hline \multicolumn{11}{|c|}{ C } \\
\hline$a=\operatorname{Pr}(\lambda<0.01 \mid y)$ & 0,011 & 0,007 & 0,006 & 0,008 & 0,011 & 0,012 & 0,011 & 0,006 & 0,011 & 0,009 \\
\hline$b=\operatorname{Pr}(\lambda>0.99 \mid y)$ & 0,003 & 0,005 & 0,006 & 0,004 & 0,003 & 0,002 & 0,003 & 0,006 & 0,003 & 0,004 \\
\hline$a / b$ & 4,485 & 1,546 & 0,933 & 2,084 & 3,733 & 5,293 & 4,222 & 1,027 & 4,184 & 2,604 \\
\hline
\end{tabular}

Źródło: obliczenia własne.

Tabela 6. Gęstość rozkładu a priori (linia ciągła) oraz a posteriori (słupki) parametru $\lambda$ w modelu FCSV dla indeksu NIKKEI 225

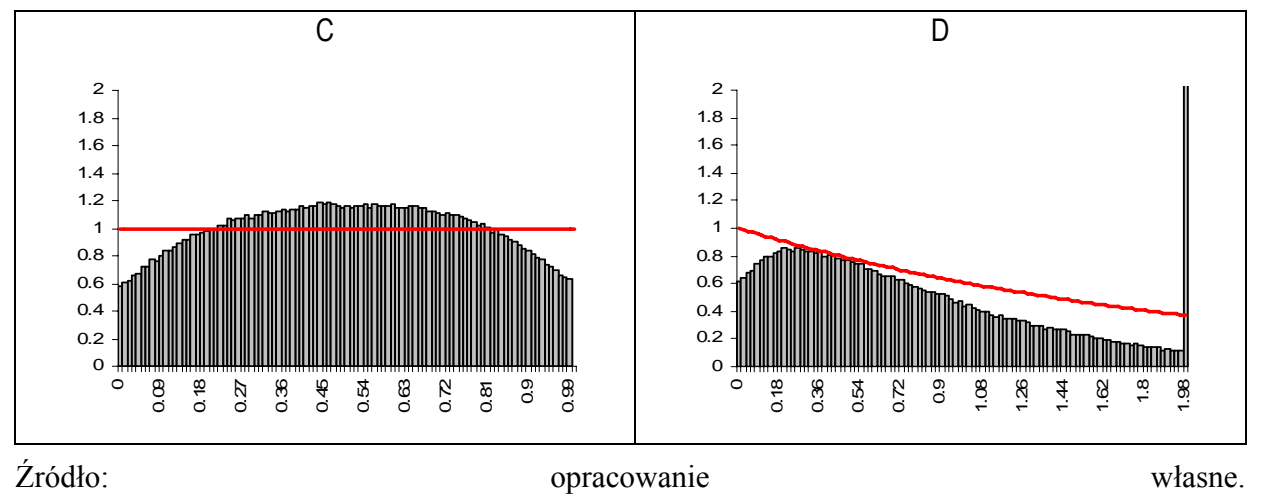


Tabela 7. Gęstość rozkładu a priori (linia ciągła) oraz a posteriori (słupki) parametru $\lambda$ w modelu FCSV dla indeksu WIG20

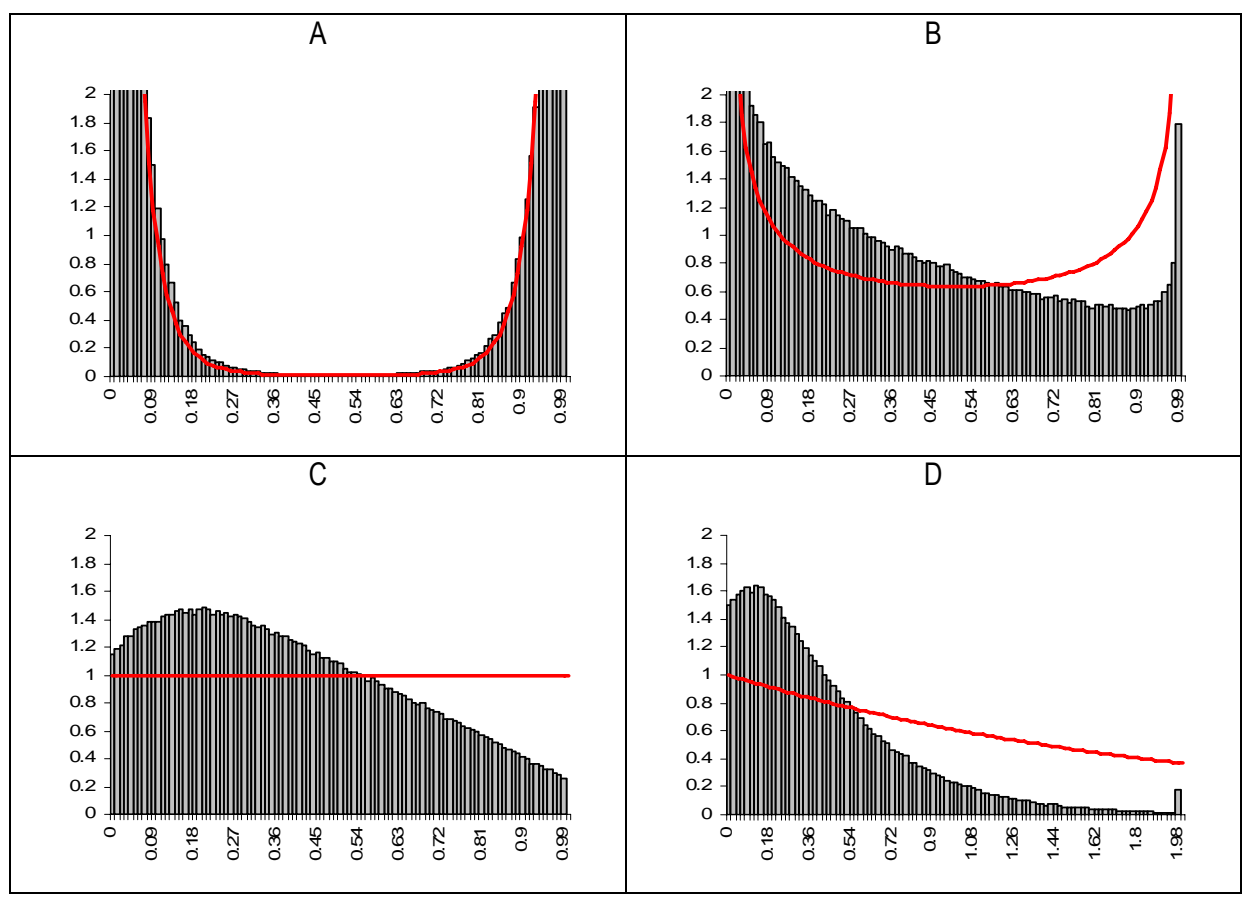

Źródło: opracowanie własne.

\section{UWAGI KOŃCOWE}

Celem artykułu była statystyczna analiza transformacji Boxa i Coxa dla danych finansowych. Wykorzystane podejście bayesowskie pozwoliło zbadać, w jakim stopniu dane modyfikują nasze wstępne przekonanie o parametrze transformacji $(\lambda)$. Uzyskane wyniki empiryczne pokazują, że rozkład a priori parametru $\lambda$ ma istotny wpływ na kształt brzegowego rozkładu a posteriori tego parametru. W większości przypadków rozkłady a posteriori, w porównaniu $\mathrm{z}$ rozkładami a priori, są jednak przesunięte w kierunku zera. Zarówno wartości bliskie zero, jak i jeden ( $\lambda=0$ odpowiada logarytmicznej stopie zwrotu, zaś $\lambda=1$ odpowiada prostej stopie zwrotu) mają niezerowe prawdopodobieństwo a posteriori. Wyniki empiryczne pozwalają przypuszczać, że w większości przypadków transformacje bliskie logarytmicznej stopie zwrotu są bardziej prawdopodobne a posteriori niż transformacje prowadzące do prostej stopy zwrotu. Jednak te ostatnie nie są a posteriori wysoce nieprawdopodobne. Podejście bayesowskie dostarcza formalnego narzędzia porównywania modeli. Wymaga ono stosowania specyficznych metod numerycznych do obliczenia wartości brzegowej gęstości wektora obserwacji. Zagadnienie to będzie przedmiotem dalszych badań. 


\section{LITERATURA}

Bauwens L., Lubrano M. (2002), Bayesian option pricing using asymmetric GARCH models, „Journal of Empirical Finance” 9, 321-342.

Duan J. -C. (1999), Conditionally Fat-Tailed Distributions and the Volatility Smile in Options, working paper, http://www.bm.ust.hk/ jeduan.

Hafner C. M., Harwartz H. (1999), Option Pricing under Linear Autoregressive Dynamics, Heteroskedasticity, and Conditional Leptokurtosis, "Journal of Empirical Finance”, 8(1), 1-34.

Härdle W., Hafner C. M. (2000), Discrete Time Option Pricing with Flexible Volatility Estimation, „Finance and Stochastics”, 4(2), 189-207.

Jacquier E., Polson N., Rossi P. (2004), Bayesian analysis of stochastic volatility models with fattails and correlated errors, ,Journal of Econometrics”, 122, 185-212.

Osiewalski J., Pipień M. (1999), Bayesowskie wnioskowanie o stacjonarności procesu GARCH(1,1), [w:] Zieliński, Z. (red.) Dynamiczne modele ekonometryczne, Wydawnictwo Uniwersytetu Mikołaja Kopernika, Toruń, 23-33.

Pajor A. (2003), Procesy zmienności stochastycznej SV w bayesowskiej analizie finansowych szeregów czasowych, Monografie: Prace Doktorskie, Nr 2, Wydawnictwo AE w Krakowie, Kraków.

Zellner A. (1971), An Introduction to Bayesian Inference in Econometrics, J. Wiley, New York.

\section{BAYESIAN ANALYSIS OF THE BOX-COX TRANSFORMATION IN FCSV MODELS}

A b s t r a c t. The continuously compounded rates of return (or logarithmic returns) and the simple rates of return are commonly used in econometric analyses of financial data. These two types of data transformation are applied arbitrarily. However, both are variants of the well-known BoxCox transformation of the $\mathrm{x}_{\mathrm{t}} / \mathrm{x}_{\mathrm{t}-1}$ ratio (where $\mathrm{x}_{\mathrm{t}}$ denotes the asset price at time $\mathrm{t}$ ) with parameter 0 and 1 , respectively.

In the paper, we consider the Box-Cox transformation of financial time series in Stochastic Volatility (SV) models. Bayesian approach is applied to make inference about the Box-Cox transformation parameter $(\lambda)$. As parameter $\lambda$ is estimated along with other unknown parameters, information in the data is used to determine which transformation is appropriate for the data. Using daily data (quotations of stock indices), we show that in the Stochastic Volatility models with fat tails and correlated errors (FCSV), the posterior distribution of parameter $\lambda$ strongly depends on the prior assumption about this parameter. It seems that in more cases the values of $\lambda$ close to 0 are more probable a posteriori than the one close to 1 .

K e y w o r d s: Box-Cox transformation, SV model, Bayesian inference 